\title{
Aplicação do índice de qualidade de aterros de resíduos sólidos urbanos no Aterro Sanitário de Puxinanã/PB
}

\section{Application of an urban solid waste landfills quality index on the Puxinanã landfill of Paraíba State, Brazil}

\author{
Suellen Silva Pereira ${ }^{a}$ \\ Rosires Catão Curib
}

${ }^{a}$ Doutora em Recursos Naturais, Universidade Federal de Campina Grande, PB, Brasil End.Eletrônico: suellenssp@hotmail.com

${ }^{b}$ Professora da Universidade Federal de Campina Grande, PB, Brasil End. Eletrônico: rosirescuri@yahoo.com.br

doi:10.18472/SustDeb.v8n1.2017.21163

Recebido em 16.11.2016

Aceito em 17.03.2017

ARTIGO - VARIA

\section{RESUMO}

A disposição final adequada dos resíduos sólidos urbanos (RSU) tem se constituído em um dos graves problemas ambientais da atualidade. Entre as formas de disposição dos resíduos, o aterro sanitário é considerado a mais adequada. Nessa perspectiva, o presente artigo objetiva analisar a sustentabilidade do aterro sanitário situado na zona rural do município de Puxinanã/PB. Para tanto, fez-se uso do Índice de Qualidade de Aterros de Resíduos Sólidos Urbanos (IQA), tendo sido este instrumento adaptado de modo a atender à realidade encontrada. Observou-se, com base nos dados coletados, que o aterro em foco não atende às normas existentes (NBR 8419/1992; 13.896/1997), possuindo condições inadequadas de funcionamento em virtude, entre outros motivos, da ausência de cobertura diária dos resíduos ali depositados; inexistência de separação e triagem dos resíduos recicláveis e compostáveis; acúmulo do lixiviado, gerando problemas ambientais e para a população, bem como contribuindo para a insustentabilidade da gestão dos RSU.

Palavras-chave: Resíduos Sólidos Urbanos. Aterro Sanitário. Sustentabilidade.

\section{ABSTRACT}

The problem of the adequate final disposal of municipal solid waste (MSW) is, nowadays, one of the serious environmental challenges. Among several different waste disposal options, sanitary land filling is generally considered the most appropriate. From this perspective, this article aims to analyse the sustainability of a landfill situated at the municipality of Puxinanã, in the Brazilian state of Paraiba. To do so, an index of landfill quality of urban solid waste (IQA) was employed. The index was adapted to match the local conditions. Following collected data, the studied landfill does not meet any existing standards (NBR 8419/1992; 13,896/1997), and exhibits inadequate operating conditions due, among 
other reasons, to the lack of daily coverage of the waste deposited there. Other negative factors included the lack of separation and sorting of recyclable and compostable waste, and the accumulation of leachate, leading to environmental and human health problems, as well as contributing to the unsustainability of solid waste management.

Keywords: Municipal Solid Waste. Sanitary Landfill. Sustainability.

\section{INTRODUÇÃO}

Sete bilhões de seres humanos geram anualmente 1,4 bilhão de toneladas de resíduos sólidos urbanos (RSU) - uma média de 1,2 kg por dia per capita. Quase a metade desse total é -gerada por menos de 30 países, os mais desenvolvidos do mundo. Se o número parece assustador, cenário ainda mais $\neg$ sombrio é traçado por estudos da Organização das Nações Unidas (ONU) e do Banco Mundial: daqui a dez anos, serão 2,2 bilhões de toneladas anuais. Na metade deste século, se o ritmo atual for mantido, se chegará a 9 bilhões de habitantes e 4 bilhões de toneladas de resíduos urbano por ano (BRASIL, 2014; GIRARDI, 2013).

Na gênese desse problema, podem ser identificados como elementos-chave o consumo crescente de bens não duráveis e o acelerado processo de concentração da população em centros urbanos, a partir dos quais o incremento constante no volume de resíduos gerados constitui um dos resultados mais visíveis, repercutindo, diretamente, na baixa oferta de serviços de coleta dos resíduos (GIRARD, 2013; LIMA, 2002; PHILLIPI JR.; AGUIAR, 2005).

A maior parte dos RSU gerados no mundo, cerca de 800 milhões de toneladas/ano, é descartada em aterros. O que compromete, de acordo com estudos da Organização das Nações Unidas (ONU), 20\% a $30 \%$ dos orçamentos municipais com a coleta e destinação desses resíduos (BRASIL, 2014).

No Brasil, conforme a Pesquisa Nacional de Saneamento Básico - PNSB, são coletadas 259.547 toneladas de resíduos sólidos domiciliares e/ou públicos diariamente (IBGE, 2010a). Apesar de mudanças significativas observadas nos últimos 20 anos, com a ampliação dos aterros sanitários, os vazadouros a céu aberto ainda estão presentes em quase $51 \%$ dos municípios brasileiros.

Nas regiões Norte e Nordeste, que concentram aproximadamente $37 \%$ da população brasileira, cerca de $50 \%$ dos resíduos coletados são depositados em "lixões", causando impactos negativos sobre os recursos hídricos, o ar e o solo, assim como na saúde pública, o que pode ser percebido quando analisada a situação do estado da Paraíba, o qual, de acordo com a PNSB/2008 (IBGE, 2010a), teve uma geração de 2.801 toneladas/dia de RSU, sendo $84,75 \%$ desses materiais encaminhados para lixões, o que demonstra que a destinação dos RSU ainda ocorre de forma precária, seguindo-se o cenário de outros municípios brasileiros, de modo a comprometer a sustentabilidade social, econômica e ambiental.

Com a publicação da Política Nacional de Resíduos Sólidos - Lei n. 12.305/2010 (BRASIL, 2010), observouse uma intensa corrida por parte dos municípios para cumprir com as metas e prazos estabelecidos na referida Lei, o que se aplica ao encerramento dos lixões e construção de aterros sanitários para disposição dos RSU, o que repercutiu em obras sem estudos técnicos e comprometimento da qualidade ambiental, caso do presente estudo.

Apesar do número de aterros sanitários em funcionamento no estado da Paraíba ser bastante reduzido, com apenas nove municípios dispondo dessa prática de disposição final dos RSU, com base no Atlas de Saneamento Básico (IBGE, 2011), a análise das condições de funcionamento desses locais representa uma contribuição pela busca da sustentabilidade da gestão dos RSU. No caso do aterro em estudo, este, apesar de estar instalado à época da realização da pesquisa, em um município de pequeno porte, recebia resíduos da segunda maior cidade do estado, o que representava um montante diário de aproximadamente 500 toneladas de RSU, isso sem considerar os resíduos das demais cidades e empresas que utilizavam o local de forma consorciada, ressaltando a importância de estudos mais aprofundados da obra em questão. 
Nessa perspectiva, o presente artigo objetivou realizar um estudo, no qual analisou as condições de funcionamento do aterro sanitário situado no município de Puxinanã/PB, por meio da aplicação do Índice de Qualidade de Aterros de Resíduos Sólidos Urbanos (IQA), como forma de verificar a sustentabilidade desse ambiente.

Para uma melhor compreensão da temática abordada, o artigo encontra-se estruturado em quatro itens principais, afora esta introdução. Na Fundamentação Teórica, buscou-se um embasamento teórico dos principais temas abordados, como forma de subsidiar uma melhor compreensão das questões discutidas. Em seguida, foi apresentado, nos Procedimentos Metodológicos, o percurso metodológico da pesquisa, assim como os instrumentos que foram utilizados. Nos Resultados e Discussão, são apresentadas as informações resultantes da pesquisa realizada (tanto de campo como bibliográfica), sendo as conclusões do estudo expostas nas Considerações Finais do presente trabalho.

\section{FUNDAMENTAÇÃO TEÓRICA}

\subsection{GERAÇÃO E DISPOSIÇÃO FINAL DOS RSU}

Quando se fala sobre a problemática dos resíduos sólidos no mundo, os números são assustadores. De acordo com levantamento realizado pela Associação Internacional de Resíduos Sólidos (ISWA, na sigla em inglês), divulgada em dezembro de 2013, os 7 bilhões de habitantes do mundo geram, por ano, cerca de 1,4 bilhão de toneladas de resíduos urbanos, mas apenas metade da população é atendida pela coleta dos resíduos (GIRARDI, 2013).

Relatório do Instituto de Pesquisa Econômica Aplicada - Ipea, de 2010, mostrou que o Brasil perde R\$ 8 bilhões por ano quando deixa de aproveitar tudo o que poderia ser reciclado e acaba encaminhado para lixões. Assim, o instituto estima que a atividade gere apenas entre $R \$ 1,4$ bilhão e $R \$ 3,3$ bilhões anuais. Somente $3 \%$ dos RSU são reciclados quando, conforme a Associação Brasileira de Empresas de Limpeza Pública e Resíduos Especiais - Abrelpe, mais de 30\% dos resíduos sólidos gerados no país apresentam potencial para a reciclagem (BRASIL, 2014).

A atividade de reciclagem fica concentrada em alguns itens específicos, como, por exemplo, a latinha de alumínio, sendo o Brasil o maior reciclador com 261 mil toneladas recicladas, o que corresponde a $98,4 \%$ (ABRELPE, 2015), sendo a compostagem ainda bastante incipiente, o que acaba por ser um contrassenso, visto que no Brasil e em muitos países subdesenvolvidos ou em fase de desenvolvimento, o resíduo domiciliar urbano é composto, na sua maioria, por materiais orgânicos biodegradáveis ou compostáveis - os quais representam mais de $50 \%$ da massa do resíduo coletado e disposto em aterros sanitários no Brasil, e apenas 1,6\% é aproveitado em processos de compostagem (BESEN, 2006; IBGE, 2010a; IPEA, 2012).

Portanto, as ações em relação ao resíduo domiciliar urbano no Brasil devem girar no sentido desta pequena porcentagem (que a depender da região estaria em torno de $16 \%$ do montante total dos resíduos gerados), ir para o aterro sanitário ou outro lugar específico para deposição de rejeitos perigosos, fato que propiciaria uma maior vida útil aos aterros sanitários, que, por vezes, sem a adequada gestão, acabam por se transformar em novos lixões.

Do montante total de resíduos gerados, apenas uma pequena parcela é encaminhada para a reciclagem; o restante é disposto, de maneira inadequada, estando os "lixões" presentes em mais de $50 \%$ dos municípios brasileiros, o que caracteriza uma verdadeira calamidade do ponto de vista sanitário e ambiental, conforme destacado na Tabela 1. 


\begin{tabular}{|c|c|c|c|c|c|c|}
\hline \multirow[t]{2}{*}{$\begin{array}{l}\text { Unidade de } \\
\text { Análise }\end{array}$} & \multicolumn{6}{|c|}{$\begin{array}{l}\text { Unidades de destino de resíduos e rejeitos urbanos considerando } \\
\text { somente disposição no solo em lixão, aterro controlado e aterro } \\
\text { sanitário* }\end{array}$} \\
\hline & \multicolumn{2}{|l|}{ Lixão } & \multicolumn{2}{|c|}{ Aterro Controlado } & \multicolumn{2}{|c|}{ Aterro sanitário } \\
\hline PNSB & 2000 & 2008 & 2000 & 2008 & 2000 & 2008 \\
\hline Brasil & 4.642 & 2.906 & 1.231 & 1.310 & 931 & 1.723 \\
\hline \multicolumn{7}{|c|}{ Estrato Populacional ${ }^{\star *}$} \\
\hline $\begin{array}{l}\text { Municípios } \\
\text { pequenos }\end{array}$ & 4.507 & 2.863 & 1.096 & 1.226 & 773 & 1.483 \\
\hline $\begin{array}{l}\text { Municípios } \\
\text { médios }\end{array}$ & 133 & 42 & 130 & 78 & 125 & 207 \\
\hline $\begin{array}{l}\text { Municípios } \\
\text { grandes }\end{array}$ & 2 & 1 & 5 & 6 & 33 & 33 \\
\hline \multicolumn{7}{|l|}{ Macrorregião } \\
\hline Norte & 430 & 388 & 44 & 45 & 19 & 45 \\
\hline Nordeste & 2.273 & 1.655 & 142 & 116 & 77 & 157 \\
\hline Sudeste & 1.040 & 317 & 475 & 807 & 463 & 645 \\
\hline Sul & 584 & 197 & 466 & 256 & 280 & 805 \\
\hline Centro-Oeste & 315 & 349 & 104 & 86 & 92 & 71 \\
\hline
\end{tabular}

*Um mesmo município pode apresentar mais de um tipo de destinação de resíduos

** Foram considerados como municípios de pequeno porte aqueles que possuíam população total menor que 100 mil habitantes; municípios de médio porte aqueles com mais de 100 mil e menos que 1 milhão de habitantes e, por fim, municípios de grande porte aqueles com população acima de 1 milhão de habitantes ${ }^{1}$.

\section{Fonte: IBGE (2002; 2010a).}

Analisando os dados mostrados na Tabela 1, entre os anos de 2000 a 2008, verifica-se que, tomando o Brasil como um todo, houve uma redução do número de Lixões (L) de $37,4 \%$, um aumento no Aterro Controlado (AC) de 6,4\% e um aumento dos Aterros Sanitários (AS) de $85 \%$. Os municípios de pequeno porte foram os que mais contribuíram para esse desempenho, uma vez que eles reduziram os $L$ em $36,5 \%$, aumentaram os AC em $11,8 \%$ e os AS em $91,8 \%$. Os municípios de grande porte reduziram os L em $50 \%$, aumentaram os $A C$ em $20 \%$ e não tiveram nenhuma atuação com relação aos AS. Então pode-se afirmar que os municípios de pequeno porte foram os que tiveram um melhor desempenho em termos de se adequarem às normas, com os de grande porte com pior desempenho.

No tocante às macrorregiões, observa-se que as regiões que mais reduziram os lixões foram o Sudeste com $69,5 \%$ de redução, seguida pelo Sul com $66,3 \%$. O Norte e o Nordeste reduziram em 9,8\% e 27,2\%, respectivamente, e o Centro-Oeste aumentou o número de lixões em 10,8\%. Com relação aos AC, o Sudeste e o Sul aumentaram em $69,8 \%$ e $45,1 \%$, respectivamente, o seu número. Com relação ao AS, o Sul, o Norte e o Nordeste aumentaram o seu número em 187,5\%, 136\% e 103,9\%, respectivamente. De se estranhar foi o desempenho da região Centro-Oeste com uma redução no número de AS da ordem de $22,8 \%$.

De forma geral, proporcionalmente às outras regiões do Brasil, a região Sudeste reduziu muito o número de lixões e aumentou muito os AC. A região Sul reduziu muito os lixões e aumentou muito os AS. O Nordeste reduziu pouco os lixões e os AC e aumentou os AS. O Norte apenas se empenhou em aumentar os AS. A região Centro-Oeste teve um desempenho que pode ser considerado muito ruim, pois aumentou o número de lixões e reduziu o número de AS e de AC. 
Há um interesse particular no número de lixões ainda existentes, pois de acordo com a Lei 12.305/2010, art. 54, "A disposição final ambientalmente adequada dos rejeitos, observado o disposto no § 10 do art. 9o, deverá ser implantada em até quatro anos após a data de publicação desta Lei" (BRASIL, 2010), ou seja, esse prazo foi encerrado em 02 de agosto de 2014, devendo esses materiais serem encaminhados, após o processo de triagem e compostagem, para aterros sanitários.

O aterro sanitário é uma técnica de disposição de resíduos no solo que visa a minimização dos impactos ambientais, utilizando, por meio de princípios de engenharia, para confinar os resíduos sólidos as menores áreas possíveis e reduzi-los aos menores volumes permitidos, sempre os cobrindo com uma camada de terra a cada conclusão (BRASIL, 2006; NBR 8419 - ABNT, 1992).

Desse modo, subentende-se que, ao adotar todas as exigências citadas anteriormente, e estando os resíduos longe dos insetos e com as substâncias contaminantes controladas, esses resíduos deixam de ser um problema para a população, principalmente para a saúde das pessoas.

\subsection{A UTILIZAÇÃO DE ÍNDICES/INDICADORES PARA AVALIAÇÃO DA QUALIDADE AMBIENTAL DOS ATERROS SANITÁRIOS}

De acordo com Monteiro (2006), os índices são instrumentos que medem cada indicador, atribuindoIhe valores numéricos, ou são resultados da combinação de várias variáveis ou parâmetros em um só valor, assumindo um peso relativo a cada componente do índice. Eles permitem observar e acompanhar a situação do meio ambiente, o impacto e as consequências dos processos de desenvolvimento sobre os recursos naturais, as funções ecológicas e as inter-relações entre os diferentes fatores do desenvolvimento.

No que concerne à utilização de índices/indicadores na avaliação da qualidade ambiental de aterros sanitários, foi possível identificar alguns estudos nessa área, sendo estes desenvolvidos em diversos municípios, com destaque, no presente artigo, de estudos que fizeram uso do Índice de Qualidade de Aterro de Resíduos - IQR (CETESB, 1997; 2015) e do Índice da Qualidade de Aterros de Resíduos Urbanos - IQA (FARIA, 2002).

O Índice de Qualidade de Aterros de Resíduos - IQR é um instrumento criado em 1997 pela Companhia de Tecnologia de Saneamento Ambiental do Estado de São Paulo (Cetesb) e, conforme expresso no Manual de Gerenciamento Integrado, IPT/Cempre (2000), é apenas exemplificativo, o que permite alterações. É composto por 41 indicadores, sendo estes divididos em três macroconjuntos: características do local, infraestrutura implantada e condições operacionais. Esse índice é plotado em um formulário, que, quando preenchido, permite alcançar uma nota que enquadra as instalações de destinação final de resíduos urbanos em três condições: inadequadas, controladas ou adequadas. Dessa maneira, permite estabelecer um critério único de avaliação nos municípios paulistas com vistas a desenvolver e aprimorar mecanismos de controle de poluição ambiental.

Faria (2002) realizou uma análise crítica do IQR visando desenvolver uma nova planilha de classificação, utilizando como instrumento a metodologia de Análise do Valor, por meio da distribuição dos pesos entre as variáveis. De acordo com a autora, a incerteza no resultado do IQR reside no seu preenchimento. A quantidade exacerbada de municípios a serem inspecionados no estado e as distâncias consideráveis entre eles demandam a participação de inúmeros técnicos do Órgão Estadual do Controle da Poluição Ambiental. E, tendo em vista o critério de avaliação pouco preciso, pode ocasionar avaliações distintas de um operador para outro, dando origem a pequenas distorções nos resultados.

A ideia de mudança, de acordo com Faria (2002), partiu do princípio de acrescentar alguns itens não contemplados, suprimir outros e reorganizá-los, estando a tabela dividida em três blocos, comportando 48 indicadores, além de modificar os intervalos da avaliação de pontos do IQR (PINTO, 2011). Essa nova tabela foi batizada com a abreviação de IQA (Índice da Qualidade de Aterros de Resíduos Urbanos) em substituição ao IQR. 


\subsection{APLICAÇÕES DO IQR E DO IQA PARA AVALIAÇÃO DE ATERROS SANITÁRIOS}

Guimarães (2009) fez uso de indicadores de qualidade ambiental para o monitoramento do aterro sanitário localizado no município de Alta Floresta (MT), entre eles, o Índice de Qualidade de Aterro de Resíduos - IQR, o qual obteve um índice de 3,2, que representa uma condição inadequada de funcionamento do aterro.

Com a finalidade de realizar um diagnóstico do aterro de disposição de resíduos do município de Taquarituba-SP, Guerra et al. (2010) empregaram a metodologia do IQR, levando-se em consideração as características do local, a infraestrutura implantada e as condições operacionais. O resultado obtido foi de 4,46, o que indicou condições inadequadas para o aterro.

Hamada (2011) fez uso do IQR para verificar a sustentabilidade de três aterros sanitários em municípios do estado de São Paulo. O município de Lençóis Paulista apresentou condição não adequada para resíduos de serviço de saúde e de construção civil, além da nota do IQR ser menor que 8,0, possuindo condições controladas de funcionamento, apesar da licença ambiental existente, o que também pôde ser observado em Bauru. Situação diferente foi diagnosticada em Sorocaba, uma vez que as licenças ambientais do aterro sanitário estão adequadas. Por isso, foi a única cidade com valor máximo para o parâmetro Licença Ambiental, com um IQR 10.

Santos et al. (2012) tiveram por objetivo aplicar o IQR para avaliar o sistema de disposição final do município de Anápolis-GO, a fim de aprimorar mecanismos de controle sanitário e ambiental. Foi possível classificar o sistema de disposição final de resíduos, em condições controladas de funcionamento, tendo como resultado a nota 8,0 (oito).

A partir da aplicação do Índice da Qualidade de Aterros de Resíduos Urbanos - IQA no aterro sanitário de Palmas-TO, Marinho e Oliveira (2013) avaliaram que a área alcançou um total de 84 (oitenta e quatro) pontos, que, com base na metodologia, gerou um índice de 6 (seis) pontos, sendo avaliado com condições inadequadas de funcionamento. De acordo com os autores, o índice gerado afirma as inadequações encontradas no aterro sanitário durante visita in loco, o que evidencia a necessidade de ações que modifiquem a forma de atuação do aterro, principalmente no que concerne às condições operacionais deste. Andrade et al. (2013) também encontraram resultado semelhante para o aterro sanitário de Palmas-TO, o que ressalta a segurança do instrumento utilizado para avaliação do aterro.

Estudo realizado por Tassinari (2016) no Aterro Sanitário do município de Contagem-MG, localizado no bairro Perobas, foi observado que o aspecto geral do Aterro Sanitário Perobas é satisfatório, porém, foram identificados pelo autor alguns requisitos que estão em desconformidade com o proposto na tabela IQR da Cetesb.

\section{PROCEDIMENTOS METODOLÓGICOS}

\section{1 ÁREA EM ESTUDO}

O município de Puxinanã está localizado na Microrregião de Campina Grande e na Mesorregião do Agreste paraibano. Além disso, está incluído na área geográfica de abrangência do semiárido brasileiro, definida pelo Ministério da Integração Nacional em 2005. A Figura 1 apresenta a localização do município no contexto do estado da Paraíba. 


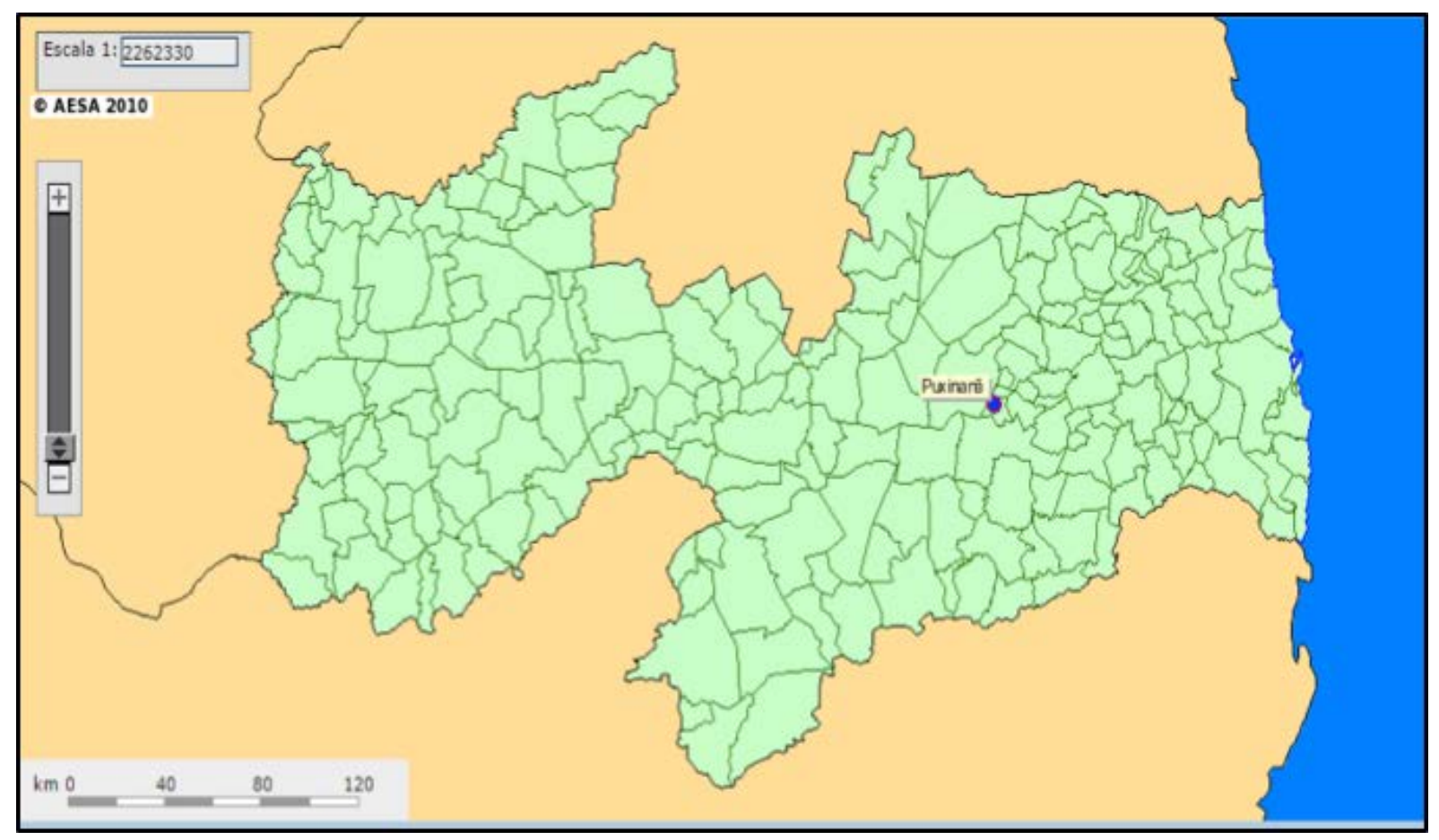

Figura 1 - Localização do município de Puxinanã no contexto do estado da Paraíba.

Fonte: AESA. Disponível em: <http://geo.aesa.pb.gov.br/>. Acesso em: Dez./2015.

De acordo com o Censo Demográfico 2010 (IBGE, 2010b), a população de Puxinanã é de 12.923,00 habitantes. Desse total, $32,63 \%$ da população reside na zona urbana do município, estando estes distribuídos em $73 \mathrm{~km}^{2}$ de área.

\subsection{CARACTERIZAÇÃO DA PESQUISA}

Do ponto de vista da sua natureza, o presente trabalho é uma pesquisa aplicada, tendo em vista que objetiva gerar conhecimentos para a aplicação prática. No que se refere à forma de abordagem, esta tem um enfoque qualitativo, visto que procura coletar dados sem a necessidade de medição numérica para descobrir ou aperfeiçoar as questões de pesquisa. Quanto aos seus objetivos, é uma Pesquisa Descritiva e Exploratória, pois, de acordo com Gil (2007), visa, além da descrição de características de determinada população ou fenômeno, proporcionar maior familiaridade com o problema com vistas a torná-lo explícito.

Em se tratando dos procedimentos técnicos adotados, a pesquisa classifica-se como: pesquisa bibliográfica, documental e estudo de campo. De acordo com Gil (2007), a diferença essencial entre a pesquisa bibliográfica e a documental está na natureza das fontes. Quanto ao estudo de campo, este "procura muito mais o aprofundamento das questões propostas" (GIL, 2007).

\subsection{INSTRUMENTO DE COLETA E ANÁLISE DOS DADOS - APLICAÇÃO DO IQA}

O presente estudo tomou como referência o Índice de Qualidade de Aterros de Resíduos Urbanos - IQA (FARIA, 2002), metodologia desenvolvida a partir da análise crítica de um índice já existente e amplamente utilizado no estado de São Paulo pela Cetesb, a saber, o Índice de Qualidade de Aterros de Resíduos - IQR.

A planilha do Índice da Qualidade de Aterros de Resíduos Urbanos - IQA é dividida em três blocos, comportando 48 indicadores. As condições que os aterros devem se enquadrar são: 
- 0 a $6,0 \rightarrow$ condições inadequadas;

- 6,01 a 8,0 $\rightarrow$ condições parcialmente adequadas;

- 8,01 a $10 \rightarrow$ condições adequadas.

As informações para o cálculo do IQA do aterro sanitário de Puxinanã-PB consistiram na aplicação do questionário padronizado desenvolvido ("check list"), considerando:

a) Características do local: capacidade de suporte do solo; permeabilidade do solo; proximidades dos núcleos habitacionais; proximidades dos corpos de águas; profundidade do lençol freático; disponibilidade do material para recobrimento; qualidade do material para recobrimento; condições dos sistemas viários, trânsitos e acessos; isolamento visual da vizinhança e a legalidade da localização;

b) Infraestrutura implantada: cercamento da área; portaria e guarita; controle de recebimento de cargas; acesso à frente de trabalho; trator de esteira ou compatível; outros equipamentos; impermeabilização da base do aterro; drenagem de chorume; drenagem de águas pluviais definitiva; drenagem de águas pluviais provisória; drenagem de gases; sistema de tratamento de chorume; monitoramento de água subterrânea; monitoramento de águas superficiais, lixiviados e gases; monitoramento da estabilidade de maciços de solo e lixo; atendimento à estipulação de projeto;

c) Condições operacionais: presença de elementos dispersos pelo vento; recobrimento diário do lixo; compactação do lixo; presença de urubus ou gaivotas; presença de moscas em grande quantidade; presença de queimadas; presença de catadores; criações de animais (porcos, bois); descarga de resíduos de saúde; descarga de resíduos industriais; funcionamento da drenagem de chorume; funcionamento da drenagem pluvial definitiva; funcionamento da drenagem pluvial provisória; funcionamento da drenagem de gases; funcionamento do sistema de tratamento de chorume; funcionamento do sistema de monitoramento da água subterrânea; funcionamento do sistema de monitoramento de águas superficiais, lixiviados e gases; funcionamento do sistema de monitoramento da estabilidade de maciços de solo e lixo; medidas corretivas; dados gerais sobre o aterro; manutenções dos acessos internos; plano de fechamento do aterro.

Registra-se que, devido ao impedimento de adentrar a área do aterro em estudo, a planilha IQA foi adaptada, no sentido de adequar os indicadores às condições da realidade pesquisada, sendo alguns dos indicadores suprimidos, modificados ou elaborados em relação à proposta original. Essas informações foram estruturadas em uma planilha, levando em consideração os três macroconjuntos de análise. A Figura 2 demonstra as informações agregadas para cada subitem/indicador, após a sua definição.

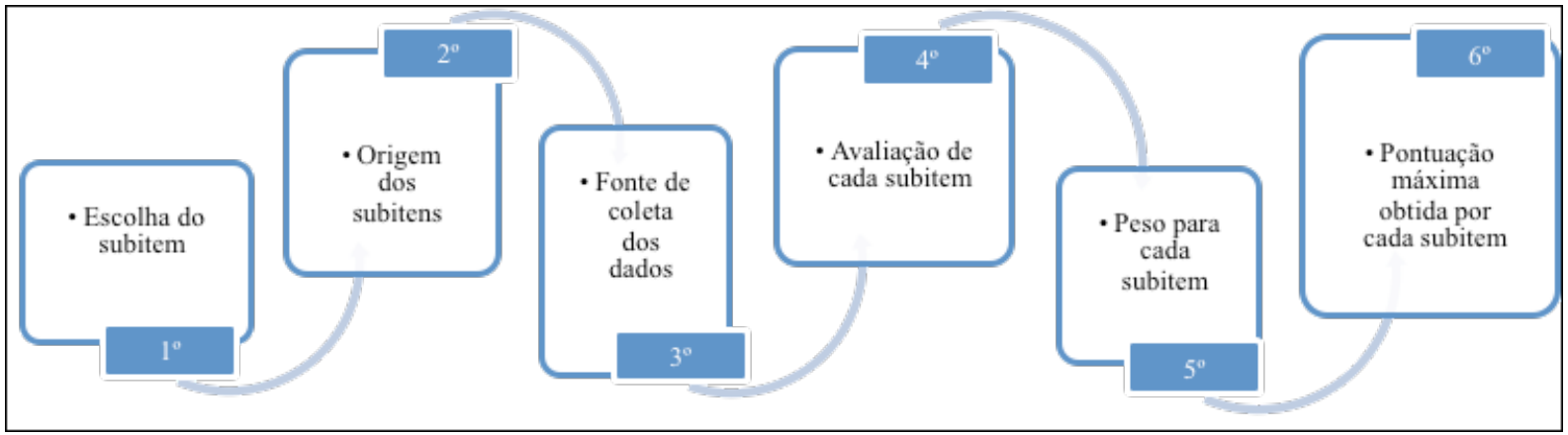

Figura 2 - Informações agregadas para cada subitem do IQA selecionado.

Fonte: Elaboração Autoras.

A escolha dos indicadores selecionados para a versão aqui apresentada tomou como parâmetro a disponibilidade dos dados por meio de levantamento bibliográfico, documental e observação in loco na área em torno do aterro sanitário. Acrescenta-se que, na preocupação de manter a estrutura do modelo IQA (FARIA, 2002), no que se refere à quantidade de indicadores utilizados, bem como na 
distribuição dos pesos destes nos três blocos de análise, foi mantida a ideia inicial, como forma de não comprometer a análise do modelo.

Registra-se que a escolha pelo IQA para aplicação no presente estudo deve-se ao fato de que esse modelo é uma versão mais atual do IQR, bem como ao fato de ter sido o intervalo de avaliação dos aterros modificado por Faria (2002), de modo a impedir a incerteza nos resultados obtidos.

\section{RESULTADOS E DISCUSSÕES}

\subsection{CARACTERÍSTICAS DO LOCAL}

O aterro sanitário da Construtora Planície está localizado no sítio Açudinho, zona rural do município de Puxinanã, com uma extensão de 80 hectares. 0 processo para instalação da obra no local data do ano de 2009, com a emissão da Certidão de Uso e Ocupação do Solo emitida pelo prefeito da época e requerimento de solicitação para obtenção de Licença de Instalação na Superintendência de Administração do Meio Ambiente da Paraíba - Sudema para efetivação do aterro.

O referido aterro recebia todos os RSU gerados pela população das cidades de Campina Grande, Puxinanã e Montadas, assim como de algumas empresas privadas, o que em termos populacionais corresponde a uma população de 409.126 habitantes atendidos, com base no Censo Demográfico de 2010 (IBGE, 2010b), população esta bastante superior à declarada quando da solicitação de instalação da obra, que foi de 40.000 habitantes, o que pode ser considerado um fato preocupante, dada a relação direta da quantidade de resíduos recebida e a vida útil do aterro.

A construção dessa obra de engenharia no município de Puxinanã-PB é envolta em contradições, desde o seu processo licitatório até à elaboração do projeto e implantação do aterro. Tais contradições (riscos ambientais provocados pela construção do referido aterro, assim como falhas técnicas encontradas no projeto de execução da obra) fizeram com que uma ordem judicial expedida pela juíza da Comarca de Pocinhos e promulgada no dia 16 de março de 2012 determinasse o fechamento do local e a interrupção da disposição dos resíduos sólidos no aterro. No dia 27 de março, atendendo à determinação judicial, o aterro foi lacrado, mas, duas horas depois, o Tribunal de Justiça da Paraíba (TJ-PB) determinou a reabertura do local, fazendo com que o aterro funcionasse por meio de liminar, atendendo a um agravo apresentado pela Construtora Planície, responsável pela gestão do empreendimento em questão ${ }^{2}$.

Tamanha polêmica em torno do aterro sanitário de Puxinanã levou o Conselho de Proteção Ambiental da Paraíba - Copam a não reconhecer a licença de operação emitida pela Superintendência de Administração do Meio Ambiente - Sudema por meio de determinação judicial, conforme parecer da 511 a Reunião Ordinária do Copam, sendo esta decisão publicada no Diário Oficial em 22 de outubro de 2011.

A NBR 13.896 de 1997 (ABNT, 1997) estabelece exigências mínimas para a localização de aterros de modo que os impactos ambientais provenientes de sua instalação sejam minimizados, a aceitação pública seja maximizada, que a área esteja dentro dos padrões de zoneamento da região e que o local possa ser utilizado por um longo período de tempo, necessitando apenas de um mínimo de obras para o início da operação. Tais exigências levam em consideração: a topografia do terreno; recursos hídricos; distância de núcleos habitacionais; critérios geológicos e pedológicos; vegetação; vias de acesso; tamanho disponível e vida útil; e custos.

Para realização da caracterização do aterro, tomou-se como referência a NBR acima exposta, assim como análise do entorno do local, haja vista que a entrada ao interior do aterro só era permitida por meio de ordem judicial. Entretanto, mesmo diante da impossibilidade de adentrar no local, era visível para todos que iam até aquele ambiente as condições irregulares em que este empreendimento realizava suas atividades, o que pode ser ressaltado pela "montanha" de resíduos existentes no local; presença de máquinas e caminhões sobre o amontoado de resíduos; ausência de compactação e cobertura desses materiais; proximidade a residências, plantações e criações de animais; além da 
existência de pequenos reservatórios de água nas imediações do aterro. A Figura 3 busca atestar tal realidade

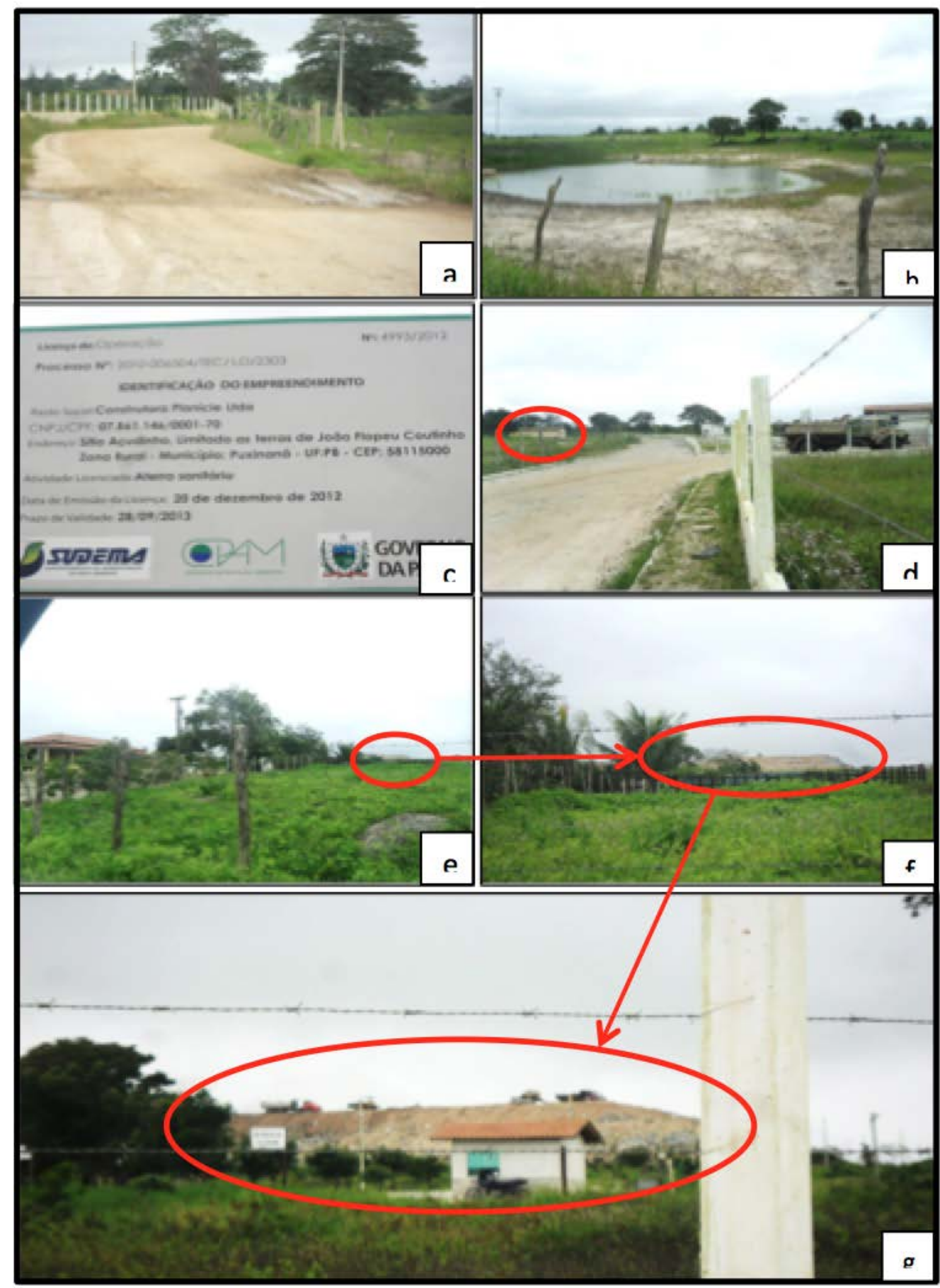

Figura 3 - Localização e caracterização do entorno do aterro sanitário de Puxinanã-PB.

a) estrada de terra que dá acesso ao aterro; b) existência de pequenos reservatórios com criações de animais; c) placa na entrada do aterro informando sobre o seu licenciamento ambiental; d) presença de casas praticamente de frente para a entrada do aterro; e) e f) presença de grande quantidade de resíduos amontoados, podendo estes serem vistos na estrada que dá acesso ao local; g) existência de máquinas e caminhões sobre a montanha de resíduos.

Fonte: Pesquisa de campo (2013).

O acesso ao aterro sanitário é feito por uma estrada de terra, ocasionando a suspenção de poeira, em decorrência da frequência e grande quantidade de veículos pesados (caminhões caçambas ou compactadores) que passaram a transitar naquela localidade para deposição dos resíduos no aterro, o 
que repercute negativamente, principalmente no que se refere aos aspectos relacionados à saúde da população do entorno.

\subsection{SISTEMA IMPLANTADO E CONDIÇÕES OPERACIONAIS DO ATERRO}

O lugar em que o aterro sanitário se encontra instalado é cercado, com a existência de uma guarita, e a entrada no local, afora os trabalhadores do aterro e dos caminhões que fazem a descarga de resíduos, só é permitida mediante ordem judicial.

Com base nas inúmeras irregularidades identificadas, a Sudema realizou uma inspeção técnica no local do aterro, em 10 de abril de 2012, como forma de observar as condições operacionais da referida obra (PARAÍBA, 2012). Entre os problemas identificados, destacam-se:

- O cano coletor de chorume está constantemente cheio e devido a problemas de encanação o chorume não está entrando na Estação de Tratamento de Esgoto (ETE); o administrador do local não tem ideia do porquê tal irregularidade está ocorrendo, e para onde está indo o chorume produzido, quanto tempo esse fato está ocorrendo e qual a vazão diária;

- O chorume está infiltrando no solo, contaminando-o e oferecendo risco de contaminação à água do lençol freático, pois a administração do aterro não está mantendo adequadamente o sistema de tratamento, coleta e disposição final de seus efluentes;

- Ademais, em relação aos dados da Sudema, constatou-se que em apenas quatro meses de funcionamento do aterro, a concentração de ferro dissolvido ( $\mathrm{mg} / \mathrm{L} \mathrm{Fe}$ ) aumentou em aproximadamente $160 \%$ (valores de dezembro - 0,42 e 0,06; valores de abril - 1,08 e 0,13), a concentração de Níquel (mg / L Ni) aumentou em até 125\% (valores de dezembro - 0,91 e 0,84; valores de abril - 1,63 e 1,89) e a concentração de Cromo VI (mg / $\mathrm{Cr}$ ) aumentou em até $50 \%$ (valor de dezembro-0,04; valor de abril-0,06).

Como resultado da inspeção técnica realizada pela Coordenadoria de Medições Ambientais (CMA) e pela fiscalização da Sudema, foi emitida a Notificação n. 001515, a qual determinava ao empreendimento "corrigir o encanamento que coleta o chorume para a lagoa, bem como apresentar a vazão de chorume do aterro, tendo um prazo máximo até o dia 17 de abril do corrente ano (2012)" (PARAÍBA, 2012), o que atesta a forma irregular com que este ambiente vinha desenvolvendo suas atividades de recebimento e disposição dos RSU, sem que houvesse qualquer tipo de tratamento, quer seja dos resíduos ou do lixiviado.

A situação do aterro sanitário tem sido motivo de debate e seus problemas vêm sendo veiculados por meio de matérias jornalísticas em emissoras locais, em virtude, entre outros motivos, do expressivo volume de resíduos acumulados no local. A Figura 4a expressa a quantidade de material existente. Outro problema evidenciado no local do aterro é a presença de uma grande quantidade de urubus, conforme demonstrado na Figura $4 b$.

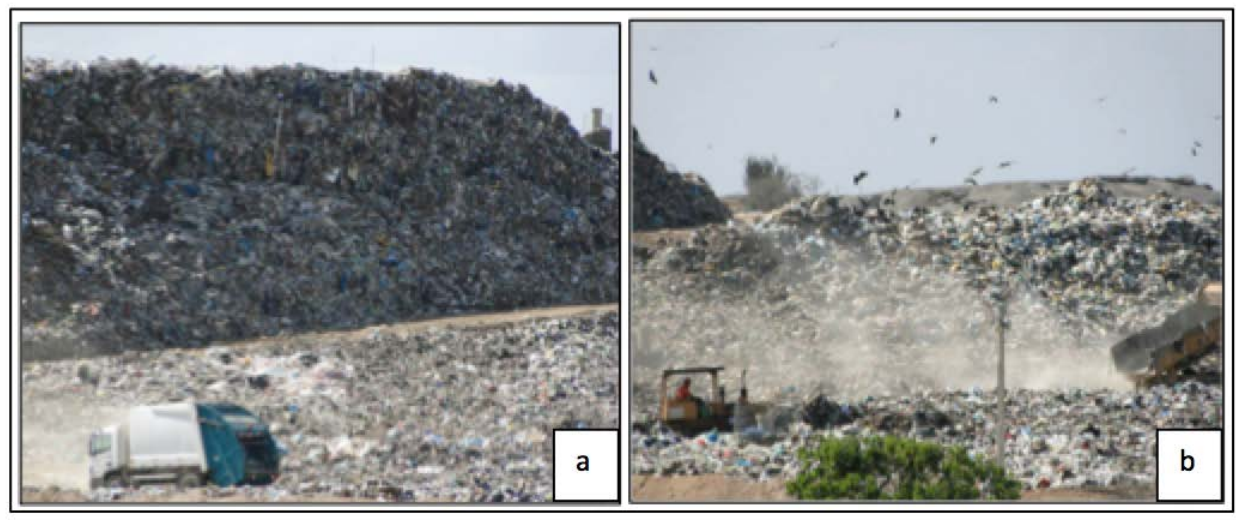

Figura 4 - Condições atuais da disposição dos RSU no aterro sanitário de Puxinanã-PB.

Fonte: Costa, 2013 apud Dantas, 2013. 
Diante das informações apresentadas, ressalta-se que um aterro sanitário, para cumprir sua finalidade e consequente benefício socioambiental, que justificaria a construção de uma obra de engenharia desse porte, levando em consideração o preconizado na NBR 8419/1992 e NBR 13.896/1997 da ABNT, deve levar em consideração uma série de recomendações com fins de proteção ambiental, a saber: sistema de impermeabilização de base e laterais; sistema de recobrimento diário dos resíduos; sistema de cobertura final das plataformas de resíduos; sistema de coleta e drenagem de lixiviados; sistema de coleta e tratamento dos gases; sistema de drenagem superficial; sistema de tratamento de lixiviados e sistema de monitoramento. O que, ao observar as imagens (Figura 4), fica evidente a ausência de tais elementos.

\subsection{APLICANDO O IQA NO ATERRO SANITÁRIO DE PUXINANÃ-PB}

Sobre a necessidade de identificar as condições de funcionamento do aterro, foi realizada uma análise no local, tomando como referência o Índice de Qualidade de Aterros de Resíduos Sólidos Urbanos - IQA (FARIA, 2002), como forma de verificar a sustentabilidade da área em estudo. O Quadro 1 apresenta as condições de funcionamento do aterro sanitário de Puxinanã.

Quadro 1 - IQA - Índice de Qualidade de Aterros de Resíduos Sólidos Urbanos do Aterro de Puxinanã-PB.

\begin{tabular}{|c|c|c|c|c|c|c|}
\hline ITEM & SUBITEM & $\begin{array}{l}\text { ORIGEM DOS } \\
\text { SUBITENS }\end{array}$ & $\begin{array}{l}\text { FONTE DOS } \\
\text { DADOS }\end{array}$ & AVALIAÇÃO & $\underset{*}{\operatorname{PESO}}$ & $\underset{* *}{\text { PONTOS }}$ \\
\hline \multirow{29}{*}{$\begin{array}{l}\text { CARACTERÍSTICAS } \\
\text { DO LOCAL }\end{array}$} & \multirow{3}{*}{ Permeabilidade do solo } & \multirow{3}{*}{$\begin{array}{l}\text { IQA (FARIA, } \\
2002)\end{array}$} & \multirow{3}{*}{ Dantas (2013) } & Baixa & 4 & \multirow{3}{*}{4} \\
\hline & & & & Média & 2 & \\
\hline & & & & Alta & 0 & \\
\hline & \multirow{2}{*}{$\begin{array}{l}\begin{array}{l}\text { Proximidade de núcleos } \\
\text { habitacionais }\end{array} \\
\end{array}$} & \multirow{2}{*}{$\begin{array}{l}\text { IQA (FARIA, } \\
2002)\end{array}$} & \multirow[t]{2}{*}{ In loco } & Longe $(500 \mathrm{~m})$ & 4 & \multirow[b]{2}{*}{0} \\
\hline & & & & Próximo & 0 & \\
\hline & \multirow{2}{*}{$\begin{array}{l}\begin{array}{l}\text { Proximidade de corpos } \\
\text { de água }\end{array} \\
\end{array}$} & \multirow{2}{*}{$\begin{array}{l}\text { IQA (FARIA, } \\
\text { 2002) }\end{array}$} & \multirow{2}{*}{ Análise doc. } & $\begin{array}{l}\text { Longe } \\
(>200 \mathrm{~m})\end{array}$ & 5 & \multirow{2}{*}{5} \\
\hline & & & & Próximo & 0 & \\
\hline & \multirow{2}{*}{$\begin{array}{l}\text { Proximidade } \\
\text { plantações }\end{array}$} & \multirow{2}{*}{ CRIADO } & \multirow[t]{2}{*}{ In loco } & $\begin{array}{c}\text { Longe } \\
(>200 \mathrm{~m})\end{array}$ & 4 & \multirow{2}{*}{0} \\
\hline & & & & Próximo & 0 & \\
\hline & \multirow{2}{*}{$\begin{array}{l}\text { Proximidade de áreas } \\
\text { com criação animal }\end{array}$} & \multirow[t]{2}{*}{ CRIADO } & \multirow[t]{2}{*}{ In loco } & $\begin{array}{c}\text { Longe } \\
(>200 \mathrm{~m})\end{array}$ & 4 & \multirow[t]{2}{*}{0} \\
\hline & & & & Próximo & 0 & \\
\hline & \multirow{3}{*}{$\begin{array}{|lr|}\text { Condições } & \text { dos } \\
\text { transportes } & \text { utilizados } \\
\text { para disposição dos RSU }\end{array}$} & \multirow{3}{*}{$\begin{array}{c}\text { Adap. IQA } \\
\text { (FARIA, 2002) }\end{array}$} & \multirow{3}{*}{$\begin{array}{c}\text { Dantas (2013) } \\
\text { In loco }\end{array}$} & Boas & 2 & \multirow{3}{*}{0} \\
\hline & & & & Regulares & 1 & \\
\hline & & & & Ruins & 0 & \\
\hline & \multirow{3}{*}{\begin{tabular}{|l|} 
Condições do trânsito \\
(tráfego de veículos para \\
disposição dos RSU)
\end{tabular}} & \multirow{3}{*}{$\begin{array}{l}\text { IQA (FARIA, } \\
\text { 2002) }\end{array}$} & \multirow{3}{*}{$\begin{array}{c}\text { Dantas (2013) } \\
\text { Análise doc. }\end{array}$} & Boas & 2 & \multirow{3}{*}{0} \\
\hline & & & & Regulares & 1 & \\
\hline & & & & Ruins & 0 & \\
\hline & \multirow{3}{*}{$\begin{array}{l}\text { Condições do acesso } \\
\text { (estrada) }\end{array}$} & \multirow{3}{*}{$\begin{array}{c}\text { Adap. IQA } \\
\text { (FARIA, 2002) }\end{array}$} & & Boas & 2 & \\
\hline & & & In loco & Regulares & 1 & 0 \\
\hline & & & & Ruins & 0 & \\
\hline & Isolamento visual dal & & & Bom & 4 & \\
\hline & $\begin{array}{l}\text { ISolamento visual daa } \\
\text { vizinhança }\end{array}$ & $\begin{array}{l}\text { IQA (FARIA, } \\
\text { 2002) }\end{array}$ & In loco & Ruim & 0 & 0 \\
\hline & Existência de FIA/Rima & CRIADO & Análise doc & Sim & 3 & 0 \\
\hline & Existencla de EIA/Rima & CRIADU & Analise doc. & Não & 0 & 0 \\
\hline & Certidão de uso $\mathrm{e}$ & Dantas & Dantas (2013) & Sim & 3 & 0 \\
\hline & ocupação do solo & (2013) & & Não & 0 & \\
\hline & Licença ambiental & CRIADO & Análise doc. & Sim & 3 & 0 \\
\hline & & & Analise doc. & Não & 0 & 0 \\
\hline & & ubtotal 1 & & Máximo & 40 & 9 \\
\hline
\end{tabular}




\begin{tabular}{|c|c|c|c|c|c|c|}
\hline & & IQA (FARIA, & In loco & Sim & 2 & 2 \\
\hline & Cercamentq da area & 2002) & & Não & 0 & 2 \\
\hline & Existência de cerca viva & Dantas (2013) & Dantas (2013) & Sim & 2 & 0 \\
\hline & & & & Năo & 0 & 0 \\
\hline & Portaria/quarita & IQA (FARIA, & $\ln$ loco & Sim & 2 & 2 \\
\hline & Pontana/guamia & 2002) & & Não & 0 & 2 \\
\hline & & IQA (FARIAS, & In loco & Sim & 2 & 2 \\
\hline & Controle de cargas & 2006) & & Não & 0 & 2 \\
\hline & lumnermeabilizacão & & & $\begin{array}{c}\text { Existe/ } \\
\text { Adequada }\end{array}$ & 4 & \\
\hline & base do aterro & (FARIA, 2002) & Dantas (2013) & $\begin{array}{c}\text { Existe/ } \\
\text { Inadequada }\end{array}$ & 2 & 2 \\
\hline & & & & Năo existe & 0 & \\
\hline & & & & $\begin{array}{c}\text { Existe/ } \\
\text { Adequada } \\
\end{array}$ & 5 & \\
\hline & Drenagem de chorume & $\begin{array}{l}\text { Adap. IQA } \\
\text { (FARIA, 2002) }\end{array}$ & Dantas (2013) & $\begin{array}{c}\text { Existe/ } \\
\text { Inadequada }\end{array}$ & 2 & 2 \\
\hline & & & & Năo existe & 0 & \\
\hline & Drenagem de áquas & & & $\begin{array}{c}\text { Existe/ } \\
\text { Adequada }\end{array}$ & 5 & \\
\hline & pluviais & (FARIA, 2002) & Análise doc. & $\begin{array}{c}\text { Existe/ } \\
\text { Inadequada }\end{array}$ & 2 & 0 \\
\hline & & & & Não existe & 0 & \\
\hline $\begin{array}{l}\text { SISTEMA } \\
\text { IMPLANTADO }\end{array}$ & & Adap. IQA & & $\begin{array}{c}\text { Existência da } \\
\text { drenagem e } \\
\text { queima }\end{array}$ & 4 & \\
\hline & queima dos gases & $\begin{array}{c}e \\
\text { Dantas (2013) }\end{array}$ & Dantas (2013) & $\begin{array}{l}\text { Existência } \\
\text { apenas da } \\
\text { drenagem }\end{array}$ & 2 & 2 \\
\hline & & & & Inexiste & 0 & \\
\hline & & & & $\begin{array}{c}\text { Existe/ } \\
\text { Adequada } \\
\end{array}$ & 4 & \\
\hline & $\begin{array}{l}\text { Sistema de tratamento } \\
\text { de chorume }\end{array}$ & $\begin{array}{l}\text { Adap. IQA } \\
\text { (FARIA, 2002) }\end{array}$ & Dantas (2013) & $\begin{array}{c}\text { Existe/ } \\
\text { Inadequada }\end{array}$ & 2 & 0 \\
\hline & & & & Não existe & 0 & \\
\hline & Condicões de trabalho & CRIADO & Análise doc. & Boas & 4 & \\
\hline & 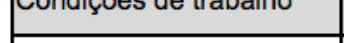 & CTIADU & Allalise uoc. & Ruins & 0 & 0 \\
\hline & Utilização adequada de & & & Sim & 4 & \\
\hline & $\begin{array}{l}\text { EFIS (Iuvas, mascaras, } \\
\text { botas, uniforme, etc.) }\end{array}$ & CRIADO & Análise doc. & Não & 0 & 0 \\
\hline & Ocorrências de & & Análise doc. & Não & 4 & \\
\hline & $\begin{array}{l}\text { entermidades } \\
\text { acidentes no local }\end{array}$ & CRIADO & & Sim & 0 & 0 \\
\hline & Plano de fechamento do & IQA & Análise doc. & Sim & 1 & 1 \\
\hline & aterro & (FARIA, 2002) & & Não & 0 & \\
\hline & Monitoramento ambiental & Dantas (2013) & Dantas (2013) & $\frac{\text { Sim }}{\text { Năo }}$ & $\frac{2}{0}$ & 0 \\
\hline & & ubtotal 2 & & Máximo & 45 & $\sqrt{3}$ \\
\hline & Recobrimento diário dos & IQA & In loco & Sim & 4 & 0 \\
\hline & resíduos & (FARIA, 2002) & & Não & 0 & 0 \\
\hline & & & & $\begin{array}{c}\text { Existe/ } \\
\text { Adequada } \\
\end{array}$ & 4 & \\
\hline & $\begin{array}{l}\text { Compactaçaoo } \\
\text { resíduos }\end{array}$ & $\begin{array}{c}\text { IQA } \\
\text { (FARIA, 2002) }\end{array}$ & In loco & $\begin{array}{c}\text { Existe/ } \\
\text { Inadequada }\end{array}$ & 2 & 0 \\
\hline & & & & Não existe & 0 & \\
\hline & Presença de urubus ou & IQA (FARIA, & In loco & Não & 1 & \\
\hline & \begin{tabular}{|l} 
gaivotas na frente de \\
trabalho
\end{tabular} & 2006) & & Sim & 0 & 0 \\
\hline & Presença de moscas em & IQA & Análise doc. & Não & 1 & 0 \\
\hline & grande quantidade & (FARIA, 2002) & & Sim & 0 & \\
\hline & Presença de animais & IQA & Análise doc. & Nẵo & 2 & 0 \\
\hline & domesticos & $\begin{array}{l}\text { (FARIA, 2002) } \\
\text { IQA (FARIA, }\end{array}$ & & $\frac{\text { Sim }}{\text { Năo }}$ & $\frac{0}{2}$ & \\
\hline & Presença de queimadas & 2002) & Dantas (2013) & Sim & 0 & 2 \\
\hline & Presença de catadores & $\begin{array}{c}\text { IQA } \\
\text { (FARIA 2002) }\end{array}$ & Dantas (2013) & $\frac{\text { Não }}{\text { Sim }}$ & 3 & 3 \\
\hline & & & & Sim & $\frac{0}{3}$ & \\
\hline & no interior do aterro & (FARIA, 2002) & Dantas (2013) & Sim & 0 & 3 \\
\hline CONDIÇŐES & Separação prévia dos & CRIADO & In loco & Sim & 5 & 0 \\
\hline OPERACIONAIS & orgânicos & UNIADU & & Não & 0 & 0 \\
\hline
\end{tabular}




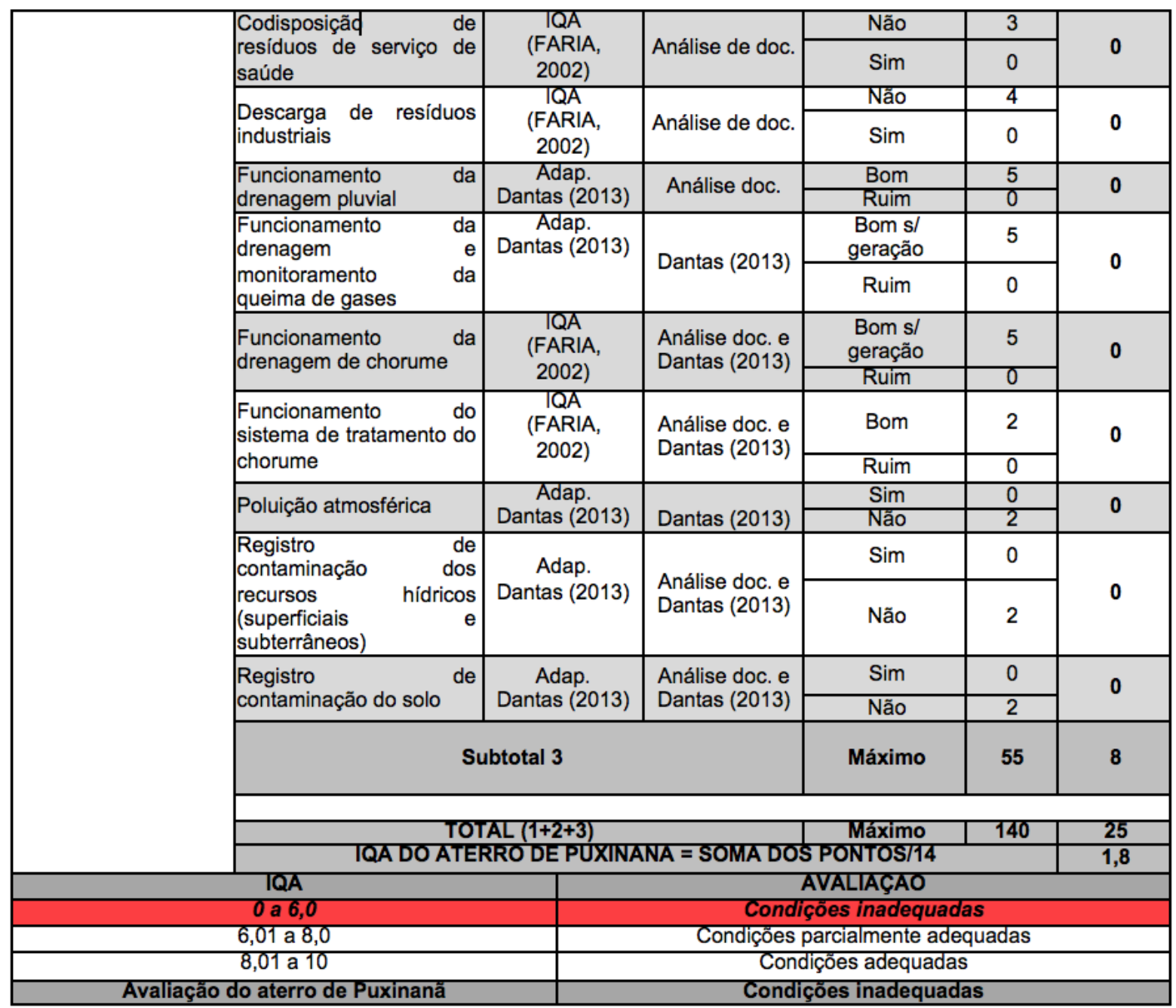

*Peso correspondente aos critérios atribuídos por Faria (2002) no IQA;

** Pontos decorrentes da avaliação dos subitens, realizada com base nas fontes de dados especificadas no quadro, levando em consideração o peso de cada subitem. Doc.: Documental.; Adap.: Adaptado.

\section{Fonte: Adaptado de Faria (2002)}

Levando em consideração os dados apresentados no Quadro 1, elaborado com base no Índice de Qualidade de Aterros de Resíduos Sólidos Urbanos - IQA (FARIA, 2002), o aterro sanitário da Construtora Planície possui condições inadequadas de funcionamento em que pesem as características do local, o sistema implantado e as condições operacionais desse empreendimento.

Ainda de acordo com o Quadro 1, tem-se que a pontuação máxima obtida pelo aterro de Puxinanã foi 25 pontos de um total de 140, sendo o item que apresentou menor desempenho, o referente às Condições Operacionais, com apenas 08 pontos de um total de 55; seguido pelo item Características do Local com 09 pontos de um total de 40; por fim, e com melhor resultado entre os demais itens analisados, encontra-se o item Sistema Implantado com 13 pontos, de um total de 45.

A obtenção do IQA ocorreu por meio da somatória dos pontos de cada item analisado, ou seja, Condições Operacionais (08) + Características do Local (09) + Sistema Implantado (13), dividido por 14, como forma de obter o total máximo de 10 (dez) pontos, quando considerada a pontuação máxima para cada item, o que não foi o caso do aterro em questão, que após a realização dos cálculos, obteve um IQA de apenas 1,8 ponto, ressaltando a deficiência do local em estudo e, consequentemente, a sua insustentabilidade. 


\section{CONSIDERAÇÕES FINAIS}

A simples implementação de um aterro sanitário por si só não garante a sustentabilidade no gerenciamento dos resíduos, haja vista que a instalação dessa obra deve ser considerada a última etapa do processo de gestão dos RSU, uma vez que o aterro sanitário tem por finalidade o encaminhamento dos rejeitos, ou seja, apenas uma pequena parcela dos resíduos é que deveria ser destinada para disposição em aterros. Ressalta-se que a instalação de um aterro sanitário repercute em significativa degradação ambiental e, por esse motivo, deve seguir normas rígidas em sua implementação e operação, além de passar, obrigatoriamente, por um processo de licenciamento ambiental no órgão ambiental competente.

O aterro sanitário da Construtora Planície, localizado no município de Puxinanã, com base nos dados apresentados, assim como nas imagens do local, descumpre exigências técnicas estabelecidas pelas normas vigentes (NBR 8419/1992; 13.896/1997), sendo estas necessárias para manter o equilíbrio ambiental da área no entorno da referida obra.

Considerando a aplicação do Índice de Qualidade de Aterros de Resíduos Sólidos Urbanos - IQA (FARIA, 2002), o aterro em estudo possui condições inadequadas de funcionamento em virtude, entre outros motivos, da ausência de cobertura diária dos resíduos ali depositados, estando os resíduos expostos a céu aberto, atraindo aves, animais e vetores transmissores de doenças; inexistência de separação e triagem dos resíduos recicláveis e compostáveis; acúmulo do lixiviado em poças, acarretando a contaminação dos recursos hídricos da região; não aproveitamento dos gases; falta de um estudo e relatório de impacto ambiental da obra na referida área, entre outras irregularidades que atestam a insustentabilidade do local, comprometendo a gestão dos RSU.

Com base nos objetivos delineados e nos resultados alcançados, o instrumento utilizado para avaliação da qualidade do aterro de Puxinanã-PB, o IQA, se apresentou satisfatório, visto que este concentra indicadores que abrangem aspectos considerados de grande relevância para a sustentabilidade do local, o que pode ser complementado com o registro visual da área.

Levando em consideração o atual quadro de disposição final dos resíduos sólidos urbanos no Brasil, necessária se faz a introdução de políticas públicas que visem à minimização da problemática em questão, haja vista os impactos socioeconômicos, sanitários e ambientais decorrentes da má gestão desses resíduos.

O que se percebe, na realidade, é que os aterros estão sendo construídos como uma solução para a problemática dos resíduos, apenas como forma de cumprir o que se estabelece na legislação atual (Lei n. 12.305/2010), enquanto o seu equacionamento é bem mais complexo e necessita de um olhar sistêmico para as questões que envolvem a temática em foco.

\section{NOTAS}

${ }^{1}$ Ressalta-se ainda que em função de não haver uma única metodologia que estabeleça critérios para dividir os municípios de acordo com a sua população, optou-se por utilizar a mesma estratificação estabelecida na Pesquisa sobre Pagamento por Serviços Ambientais Urbanos (Psau) para a Gestão dos Resíduos Sólidos do Ipea, que também se aproxima ao adotado no Programa Pró-Municípios do Ministério das Cidades.

2 Disponível em: <http://g1.globo.com/pb/paraiba/noticia/2012/03/justica-fecha-e-abre-aterro-sanitario-da-regiao-de-campina-grande-em -2h.html>. Acesso em: 20 abr. 2012.

\section{REFERÊNCIAS}

ANDRADE, T. C. C. et al. Aplicação de uma ferramenta de gestão ambiental de qualidade de aterros de resíduos sólidos urbanos. In: Revista de Ciências Ambientais, Canoas, v.7, n. 2, p. 45-56, 2013.

ASSOCIAÇÃO BRASILEIRA DE EMPRESAS DE LIMPEZA PÚBLICA E RESÍDUOS ESPECIAIS. Panorama dos Resíduos Sólidos no Brasil - 2015. Disponível em: <http://www.abrelpe.org.br/Panorama/panorama2015.pdf>. Acesso em: 28 fev. 2017. 
ASSOCIAÇÃO BRASILEIRA DE NORMAS TÉCNICAS. NBR 8419: apresentação de projetos de aterros sanitários de resíduos sólidos urbanos. Rio de Janeiro, 1992.

NBR 13896: aterros de resíduos não perigosos - critérios para projeto, implantação e operação. Rio de Janeiro, 1997.

BESEN, G. R. Programas municipais de coleta seletiva em parceria com organizações de catadores na Região Metropolitana de São Paulo. Dissertação (Mestrado) - Faculdade de Saúde Pública da Universidade de São Paulo, São Paulo, 2006.

BRASIL. Agência Nacional de Vigilância Sanitária. Gerenciamento dos Resíduos de Serviços de Saúde. Ministério da Saúde, Agência Nacional de Vigilância Sanitária. Brasília: Ministério da Saúde, 2006.

Presidência da República. Casa Civil. Lei n. 12.305, de 02 de agosto de 2010. Institui a Política Nacional de Resíduos Sólidos e dá outras providências. 2010.

Senado Federal. Resíduos sólidos: os lixões persistem. In: Revista em Discussão! Ano 5, n. 22, set. 2014.

COMPANHIA DE TECNOLOGIA DE SANEAMENTO AMBIENTAL. Governo de São Paulo. Secretaria de Meio Ambiente. Aterros sanitários em valas. São Paulo, 1997.

Governo de São Paulo. Secretaria de Meio Ambiente. Inventário Estadual de Resíduos Sólidos Urbanos - 2014. São Paulo: Cetesb, 2015. 126p.

DANTAS, E. R. B. Análise do processor de implementação e operação do aterro sanitário no município de Puxinanã-PB utilizando o sistema de indicador de sustentabilidade pressão-estado-impacto-resposta (P-E-I-R). Dissertação (Mestrado) - Universidade Federal de Campina Grande. Programa de Pós-Graduação em Engenharia Civil e Ambiental. Campina Grande, 2013.

FARIA, F. dos S. Índice de qualidade de aterros de resíduos urbanos. Tese (Doutorado) - Universidade Federal do Rio de Janeiro, Coppe. Rio de Janeiro, 2002.

GIL, A. C. Como elaborar projetos de pesquisa. 4. ed. São Paulo: Atlas, 2007. p. 175.

GIRARD, G. Metade do mundo não coleta lixo, mostra pesquisa. In: Exame.com. Ambiente. Publicado em 26/11/ 2013. Disponível em: <http://exame.abril.com.br/mundo/noticias/metade-do-mundo-nao-coleta-lixo-mostrapesquisa/>. Acesso em: 30 nov. 2013.

GUERRA, A. F. et al. Proposta de melhoria de aterro de resíduos sólidos urbanos para um pequeno município. In: Rev. Acad., Ciênc. Agrár. Ambient., Curitiba, v. 8, n. 2, p. 191-203, abr./jun. 2010, p. 191-203.

GUIMARÃES, C. P. Aplicação de indicadores da qualidade ambiental em um aterro sanitário no norte de Mato Grosso. Dissertação (Mestrado) - Universidade Federal de Mato Grosso. Instituto de Física. Programa de PósGraduação em Física Ambiental. Cuiabá, MT 2009.

HAMADA, P. Formulação de um índice de qualidade de gestão de resíduos sólidos. Dissertação (Mestrado) Universidade Estadual Paulista. Faculdade de Engenharia, Bauru, 2011. $111 \mathrm{f}$.

INSTITUTO BRASILEIRO DE GEOGRAFIA E ESTATÍsTICA. Pesquisa Nacional de Saneamento Básico 2000. Banco Multidimensional de estatística, 2002. Disponível em: <http://www.bme.ibge.gov.br>. Acesso em: 12 nov. 2012.

Pesquisa Nacional de Saneamento Básico - 2008. Ministério do Planejamento, Orçamento e Gestão. Instituto Brasileiro de Geografia e Estatística - IBGE. Rio de Janeiro, 2010a.

Censo Demográfico 2010. Ministério do Planejamento, Orçamento e Gestão. Instituto Brasileiro de Geografia e Estatística - IBGE. Rio de Janeiro, 2010b.

Diretoria de Geociências. Atlas de Saneamento 2011. Rio de Janeiro, 2011. 
INSTITUTO DE PESQUISA ECONÔMICA APLICADA. Relatório de Pesquisa. Diagnóstico dos Resíduos Sólidos Urbanos. Disponível em: <http://www.ipea.gov.br/agencia/images/stories/PDFs/relatoriopesquisa/121009_ relatorio_residuos_solidos_urbanos.pdf>. Acesso em: 28 fev. 2017.

IPT/CEMPRE. Lixo Municipal: manual de gerenciamento integrado. São Paulo: Instituto de Pesquisas Tecnológicas/ IPT, 2000.

LIMA, J. D. Gestão dos Resíduos Sólidos Urbanos no Brasil. João Pessoa: Abes, 2002.

MARINHO, R. C.; OLIVEIRA, R. M. S. Avaliação da qualidade do aterro sanitário de Palmas-TO, utilizando a ferramenta índice da qualidade de aterros de resíduos - IQA. In: Revista Nacional de Gerenciamento de Cidades, v. 01, n. 02, p. 123-141, 2013.

MONTEIRO, A. E. Índice de Qualidade de Aterros Industriais - IQRI. Dissertação (Mestrado em Engenharia Civil) - Universidade Federal do Rio de Janeiro, Coppe, Rio de Janeiro, 2006, $201 \mathrm{f}$.

PARAÍBA. Governo do Estado da Paraíba. Superintendência de Administração do Meio Ambiente - Sudema. Relatório Técnico de Inspeção no Aterro Sanitário de Puxinanã e Monitoramento dos Corpos de Água do Entorno. João Pessoa, 2012.

PHILLIPI JR., A.; AGUIAR, A. de. Resíduos sólidos: características e gerenciamento. In: PHILLIPI JR., A. (Org.). Saneamento, saúde e ambiente: fundamentos para um desenvolvimento sustentável. São Paulo: Manole, 2005, p. 267-322.

PINTO, D. P. de S. Contribuição à avaliação de aterros de resíduos industriais. Dissertação (Mestrado em Ciências em Engenharia Civil) - Universidade Federal do Rio de Janeiro, 2011. 162p.

SANTOS, A. L. F. et al. Índice de qualidade de aterro de resíduos (IQR), como subsídio para avaliar o sistema de disposição final do município de Anápolis-GO. In: Scientia Plena, v. 8, n. 10, p. 1-20, 2012.

TASSINARI, D. IQR - Índice de Qualidade de Aterros: aterro sanitário Perobas em Contagem/MG. Publicado em 15 de outubro de 2016. Disponível em: <https://denilsontassinari.blogspot.com.br/2016/10/iqr-indice-dequalidade-de-aterros_15.html?m=0>. Acesso em: 28 fev. 2017.

UN-HABITAT. Programa da Organização das Nações Unidas para Assentamentos Humanos (UN-HABITAT). Solid Waste Management in the World's Cities. New York: United Nations Publications, 2009. 